\title{
Performing Society: Pursuing Creativity and Criticality in Secondary ELA
}

Stephanie Ho

\begin{abstract}
As an English Language Arts teacher, I have experienced cost-effective approaches replacing the actual "arts" of ELA (Trend, 1992). This article explores how Surrealist-oriented pedagogies could restore imaginative freedom and deconstruct conceptual barriers (normative standards, curricular constraints, and status quo power relations) in secondary ELA. I will also examine how we can use Surrealism as a political and pedagogical model to treat societal problems mirrored in ELA classrooms. Surrealist-oriented pedagogies could enable students to experiment with social issues and develop senses of agency and voice that reflect awareness of contemporary society while simultaneously building their ELA skills.
\end{abstract}

\section{Background}

The concept of performance connotes ideas of physicality in artistic expression. In this vein, performance in education can sometimes be positioned outside (rather than alongside) traditional pen-and-paper modes of teaching and learning. While I fully agree with the idea that fine art mediums provide exciting educational opportunities, I wonder if performance can involve exclusively mental movement and still be progressive. In other words, do we need to move the body in order to perform, or can we flex the brain and still demonstrate impact?

As an English teacher, I have never been gifted in the dramatic arts, and have on a number of occasions cringed at the sound of my recorded voice. I don't consider myself graceful and cannot remember musical scores to save my life; and this comes after having completed 14 years of force-fed piano lessons. Recently, I visited the McGill Art Hive and found myself overwhelmed with stress-not because our performance activities (aimed at relaxation) were not well constructed-but because the artist in residence was so profoundly calm and, dare I say, artistically enlightened in aura. I felt pathetically drab and conventional in relation to this woman, whose speech seemed to flow freely and in perfect synchronicity with her body movements. As she described peaceful breathing strategies, all I could notice were my untanned bare feet and my seeming incompatibility with revolutionary education.

Following this recognition of my own artlessness, I began to examine my practice in relation to the Art Hive's freedom. I then realized that while I will probably never succeed in implementing song and dance into my study of a play, I was slightly shortchanging my pedagogy in deeming it "traditional." Despite the reputation of senior-level students being unmotivated and checked-out of their learning, my class has, at times, offered great fulfillment with its discussion and inquiry. It seems then, that in a far less aesthetically impactful manner, I have been aiming to create an educational hive of my own. To discount 
myself as "nonperformance oriented" was possibly a quick assessment, and perhaps our idea of performance could be expanded to fit varying situations. In my mind, while some forms of performance involve displaying colours and dramatic gestures, others can involve sitting still and imaginatively expressing these concepts. In fact, rather than solely involving an impactful end product, performance, in my mind, involves active processes, and new modes of expression. Performance is not stagnant, and the movement involved can take place in the mind. Also, performance is unquestionably artistic in nature, and I feel my English Language Arts classroom is hungry for art. Hence, I have become increasingly interested in my own form of performance education, one that involves creating educational spaces where our students' brains can work through the complexities of our everyday human condition; essentially, within my class, I aim for students to perform society.

While my English class has at times succeeded in forming a hive, buzzing with creative potential, these moments are unfortunately not commonplace. I frequently refer to these magic moments of critical coalescence, where all educational stars seem to align, as our "nuggets of brilliance." I revisit these nuggets on a regular basis, attempting to motivate students through an acknowledgement of their own intellectual power. The problem, however, comes in how these moments get spread out over the course of a year, systematically losing their magic within lacklustre learning contexts. The idea that students aren't actively accessing their critical potential became apparent to me through a disappointing classroom experience. Earlier on this year, my students and I engaged in a group reading of Tennessee Williams' play Cat on a Hot Tin Roof. While the story was meant for theatrical performance, we examined it from our context of literary analysis. I was saving a particularly juicy passage for my students, expecting they would appreciate the dysfunctional messiness of it. Within the passage, Maggie, the protagonist, frustratingly recounts her extramarital affair to her husband Brick, a presumed closeted homosexual. To make matters worse, Maggie allegedly made love to Brick's best friend-who also shared romantic feelings for her husband. I read aloud the passage where Maggie describes the encounter in an uncomfortable and desperate manner. I built up to the climax of the moment, using air quotations and strategic pauses to emphasize Maggie's comment that the exchange "didn't work." To my unexpected surprise, the response to this juiciness was pure silence. I repeated the passage again multiple times, asking the students what they thought of the fact that it "didn't work" between Maggie and Skipper. Finally, one of my students raised her hand and said, "Ms. Ho, can you just give us the answer?" I was shocked. When asking my students what they thought of this passage, they expressed a belief that ELA, which to me is emblematic of human experience and emotions, has a single answer.

I wondered who was to blame for this lack of criticality in my ELA classroom. Was it me, the teacher? I didn't think I was short on enthusiasm and I had made an effort to find a picture of human experience that could rival the drama of a Netflix series. Was the problem, then, the institution? I recognize we have curricular and time restraints, but unlike public school teachers, my context allows me decent financial freedom in my practice. Perhaps the problem was the ubiquitous "society at large." If so, I wondered why that was the case, and how our societal context was faulty to the point where its trickle-down effect could be so artless. I realized the answer lay in not committing the same erroneous flaw that my students presented. If ELA does not have a single answer, nor do the problems of ELA education. 
This understanding that the systematic de-criticalization of our ELA classes is a matter of joint blame, shared amongst many parties (including myself), opened up a new realm of intellectual inquiry. Acknowledging my complicit nature in deflating my ELA class of its creative potential prompted my quest for a revolutionary solution. This is what brought me to the historic movement of Surrealism, which was originally aimed at eliciting authentic, unhinged thought and expression. Surrealism was an active movement and its philosophy purports that human beings, due to social, political, and cultural shaping, are not free thinkers; thus, we need to reclaim our imaginative emancipation by embracing a new dimension of reality.

\section{Surrealist Play as Theory}

I therefore aim to create a new, Surrealist-oriented pedagogical style to meet the needs of ELA classrooms lacking in creativity and criticality. Based upon antisociety, anticapitalist, and anticonventional beliefs, Surrealism involves an aggressive attack on reality (Breton, Seaver, \& Lane, 1972). Led by Andre Breton in the 1920s, Surrealism as a philosophical practice was born in Paris and branched from existing societal critique intrinsic to the Dada movement (Marantz \& Rubin, 1969). Within my practice, this exact societal critique is severely lacking, despite being a goal imbedded within our curriculum. As a result, our ELA curriculum has been reduced to a measurable science, with standardized evaluation tasks favouring efferent reading (MEES, 2019; Rosenblatt, 2005). My ELA reality made me wonder how my discipline deviated so far from the artistic freedom necessary to build the autonomous, critical agents we aim to form. I then, in an effort to form a holistic understanding of my ELA problem, extended my exploration to the inherently economic societal context housing our schooling system (Davies \& Bansel, 2007). If we consider our classrooms to be units mirroring the neoliberal values of society at large, we may begin to determine why our language arts education has morphed into a language science. This brings me back to our need, as ELA teachers, for a revolt of sorts that can help reclaim the artistic power we are missing. We need to begin deconstructing the formulaic models that limit and dictate the possibilities of ELA, much like how the historic Surrealists fought for the power of artistic thought and expression under the guidance of Breton (Breton et al., 1972). However, the impetus of a historic artistic movement, though it be political in nature, does not form a linear connection with the artistic needs of modern classrooms. This gap prompted me to consider theories of critical, radical pedagogy. Within this domain, figures such as Giroux (1988) attack hegemonic neoliberal contexts in order to liberate educational freedom, just as Breton and colleagues (1972) fought in the name of artistic emancipation.

This stream of consciousness presents a web of seemingly disjunctive, yet evidently influential, bodies of thought. Therefore, in this paper, I plan to engage in an act of theoretical, Surrealist play (Marantz \& Rubin, 1969), where I will form meaningful associations between the conceptually distant bodies of Surrealism, contemporary ELA classrooms, and Critical Pedagogy. I will begin with an exploration of neoliberalism as a political construct, whose ideologies can be used to analyze the construction of classroom communities. Next, I will explore Critical Pedagogy, an ideological framework that critiques the operations of neoliberal societies and the presumed negative effects they have on education. 
I will explore Critical Pedagogy with the goal of better understanding my own politically charged ELA context, while perhaps discovering some solutions to reintroduce the missing "arts." Finally, I will explore Surrealism, an artistic movement which targets reality and conformity in the name of artistic liberty. I aim to illuminate how Surrealism is not confined to its original historic school, but instead is ongoing, and worthy of revisiting in light of dilemmas in contemporary classroom practices. Through my Surrealist play and the formation of spontaneous connections, I endeavour to forge a new theoretical framework for examining contemporary ELA education. I also aim to justify the need for Surrealist-centered pedagogies, while illuminating theoretical gaps in need of further research.

\section{Neoliberal Practices in ELA}

Within our neoliberal societal model, our ELA curriculum has become a system of targeted skills building and efferent reading. Efferent reading involves reading solely for the attainment of information, rather than development of interpretive skills (Rosenblatt, 2005). This method limits ELA to a series of procedural tasks, rather than the more educationally interactional experience of reading with the intent of entering into a story and reflecting on its personal significance. An example of an assignment that calls upon efferent-reading strategies is the Secondary ELA Reading Response. While the Quebec Education Program (QEP) has illustrated the analysis of texts to be a holistic endeavour that "represent[s] sociocultural values and beliefs, promot[ing] viewpoints and influenc[ing] our actions in society" (MEES, 2019, p. 32), I have observed the formation of step-by-step categories to result in fragmented, checklist-style reading methods. Rather than reflecting on the personal significance of aspects such as writing techniques and themes, this categorization of different textual elements has, in my experience, caused students to read in a tunnel-vision style. Consequently, students become passive scavengers, rather than active agents engaging with a body of textual work. The text thus becomes divorced from the real world by virtue of our unwillingness to bring it to life. Rosenblatt (2005) has illustrated the difference between the efferent reading practices evidenced in our current ELA education, as opposed to aesthetic reading practices. Rosenblatt has also prefaced that literature is closely related to human experience. Therefore (neoliberal) didactic, moralistic methods of teaching literature stifle the possibilities of aesthetic, transactional reading. The efferent practice of reading to attain an established body of information eliminates the power of the reader. The reader, who, in this case, is my ELA student, with his or her past experience and ongoing life experience, brings to a text a specific angle from which to read and interpret. The engagement between a text and the unique reader (with his or her body of knowledge) forms a new experience and thus, the creation of meaning. Writers can elicit emotions through stories, presenting a particular perspective in response to our shared world. The reader thus participates in the vision of the writer, using it to make sense of his/her lived experience outside of the text. The relationship that takes place between the reader and writer forms an imaginative experience when the reader becomes focused and absorbed by his/her feelings in response to the stimulus of the text. This imaginative freedom is the central aim of Surrealist theory (Breton et al., 1972) and is notably lacking from contemporary ELA education. Therefore, we can observe how the objectives of the historic artistic movement, itself entrenched in emancipatory struggle, speaks directly to ongoing challenges observable in the arts and artistic educational disciplines. 
Performing Society: Pursuing Creativity and Criticality in Secondary ELA

\section{Critical Pedagogy and Secondary ELA}

Within my Secondary ELA practice, I have the responsibility to present students with a window into their world. The frame in which I set that window could confirm the method of market-oriented societal preparation, or conversely, critically engaged social activism. In a sense, ELA is about storytelling, as we simultaneously deconstruct works of literature and the stories of society. The power of ELA lies, as illustrated in the QEP's mandate (MEES, 2019), in representing societal values within the school place and recognizing their role in shaping our actions as individuals. However, there stands an apparent disparity between the theory and practice of the QEP's intended goals. I feel that identifying why this critical engagement with societal values is not happening to its fullest potential, lies in first recognizing restrictive practices such as standardized, procedural assignments. Secondly, however, approaching ELA from a standpoint of Critical Pedagogy can help us engage with the storytelling we have been doing, thus illuminating its restricted nature. Trend's (1992) perspective on knowledge as static currency speaks to our closed nature of storytelling. Essentially, through this hegemonic narrative, there lies one story and one way of telling it. Culture, and the messages transmitted through stories, are stripped of their transactional value, and presented in a singular way that supports a dominant discourse. This discourse often communicates settler white, male, heteronormative ideologies, while actively suppressing the voices of people such as ethnic minority groups, women, non-gender binary individuals, and Indigenous Peoples. What I feel is missing alongside creativity and criticality in my classroom, is not a recognition of this hegemonic system, but rather, a frank interrogation and subversion of it. My disempowered ELA teacher peers could therefore reignite imaginative fire in their classes by forging an honest dialogue about the oppression that comprises our societal institutions and everyday practices (Rose \& Kincheloe, 2003; Trend, 1992). By forming a critical discourse around which to frame our existence, we are not only subverting our artistic disenfranchisement in a highly Surrealist manner (Breton et al., 1972), but also bringing our ELA storytelling to life. Asking questions and interrogating common-sense narratives can not only encourage students to fulfill the aims of the QEP, by examining societal values in relation to identity and the self, but also voice the stories that have been silenced by the canonical framework of "proper" education (Rose \& Kincheloe, 2003; Trend, 1992). For example, when interacting with Cat on a Hot Tin Roof, we may choose to ask questions surrounding Brick's presumed hidden sexuality. We could examine ideas of masculinity as a social construction, and consider why a 1950s white man of nonconforming sexual orientation may have felt the need to conceal his identity. This conversation could open the floor for a discussion about our own contemporary society and the degree to which we can witness a legacy of established, restrictive ideologies such as those witnessed in the play. Finally, imperative in this discussion would be a consideration of why, if it is indeed the case, certain ideologies such as racism, homophobia, and sexism, continue to perpetuate our everyday discourses, despite us living in an "advanced," forward-thinking society. Essentially, becoming critical educators, and I mean this in no hyperbolic sense, can save our students from complacency and social stagnancy. Critical pedagogy operates on the educational scale, within classrooms, just as Surrealism operates on the artistic domain. Breton and his Surrealists created their manifestoes and revolutionary movement to reclaim artistic autonomy and most importantly, the freedom of thought (Breton et al., 1972). Breton based his movement upon a belief that our thought has been hinged via the barriers of 
living in conformist, politically charged societies. As Rose and Kincheloe (2003) had highlighted the delegitimization of certain art forms, Breton called to question the same dismissal of artistic practices of expression. Expression, according to Breton, is an artistic gift linked to humanity and our understanding of the world. If our expression becomes blocked, it is likely that our thought processes have also been blocked, and this is the epitome of artistic imprisonment. We, in ELA, aim to attach the same respect to the imagination as Breton has done. His aims for democratic emancipation of the mind mirror the views of Trend, Giroux, and Rose and Kincheloe in terms of liberating the education domain. As such, I feel the subversive strategies of Critical Pedagogy aimed at the classroom, could serve in bridging the similarly subversive aims of Surrealism aimed at the art domain, forming a joint conversation that could speak to the needs of my artless ELA classroom.

\section{Surrealism in ELA}

In our current ELA classrooms, our initial concern may be a practice-oriented one, as we feel logistical barriers restrict the way we act. However, if we were to more critically dissect our positions as educators, we would notice our own role in supporting these barriers. Breton's (1972) radical devotion to Surrealism, and his constant efforts to define and redefine the constituents of the movement and its philosophy, were all aimed at helping man reclaim his most powerful possession: his mind. It may be tempting to examine the Surrealist movement solely based upon the art produced under its name; however, these revolutionary works do not independently speak to the political nature of the cause. To examine them as such would be to view the problems of contemporary ELA in complete isolation from the sociopolitical issues surrounding it. Likewise, to view the artistic works of Surrealists as the end goal of the movement would be problematic, since it would involve an interpretation of the movement as solely arts oriented. The work of Surrealist artists, rather, should communicate the charged freedom for which Breton has advocated, as these pieces form a subversive statement about the power of automatism (Breton et al., 1972). These works are not the end product, since the ultimate goal of Breton's fight was achieving purely unaffected thought and expression. One could argue that a sole focus on Surrealist works, rather than a joint examination of them in conjunction with Breton's manifestoes, would produce a "chicken and the egg" problem, resulting in a misaligned understanding of the movement. If we therefore shift our gaze and recognize pure automatism to be a tenet of the movement, we could consequently begin reconceptualizing our own ELA problem. In fact, focusing on logistical restraints such as the need for standardized testing, in addition to seemingly dehumanizing realities such as class sizes and funding, would be to examine Marcel Duchamp's Fountain (Marantz \& Rubin, 1969) as a purely artistic, rather than political and emancipatory, work. The point is not the restraints surrounding our practices; the point is the impact these restraints have on our ability to free students' minds in a Bretonian manner. Therefore, our solution must take into account this conceptual web, since a solution does not lie in simply dismantling unsavoury boundaries. Hypothetically speaking, if we were to abolish standardized testing in ELA education, the noncritical educator would then ask: "Now what?" In fact, I feel a sustainable solution in achieving creativity and criticality in ELA education, and to free students' minds, making them sensitive and tuned in to their societal surroundings, is to use our own minds. Subversive thinking, and Critical Pedagogy (Giroux, 1988; 2016), could therefore operate in thinking our way out of our 
conceptual bounds. As previously noted, we are maintaining our own imprisonment by not analyzing its structure (Davies \& Bansel, 2007). By coming together in a collective manner, like Breton's Surrealists (1972), ELA teachers have the potential to create a political movement of our own, one aimed at liberating our domain and restoring its artistic power. ELA educators cannot continue to silently struggle in isolation, resigned to an idea that change is impossible. We must harness the fire of Critical Pedagogy, question our subjugation, and intellectually rise above the structures that have made technicians (Trend, 1992) of us artists.

\section{Surrealist Play as Practice}

My act of creating a new conceptual framework from which to interpret problems in ELA education was a matter of theoretical performance play. Following this play, however, my theory demands to be enacted within the field, and be transformed into an act of experiential performance. I plan on creating an environment of Surrealist imaginative play, where students can be free to stretch their perspectives much like I created my theoretical framework. My unit will take place over the period of one secondary school term. I will begin the unit with an overarching lesson on the historical movement of Surrealism. Following this lesson, students will have the opportunity to experiment with creative Surrealist-oriented activities such as the creation of found poetry or Surrealist-style collages. I will then aim to contextualize the philosophy of this political movement into a modern-day context-specifically, within our ELA classroom. I will then solicit students' thinking about the politics and hierarchical structures that surround their lives, ranging from the context of the private school to its place in the larger society. Within this discussion, students can examine power dynamics ranging from students and teachers to citizens and politicians. After having sufficiently formed a base of political inquiry, I will present all preexisting aspects of the curriculum through a Surrealist critical lens. For example, when students learn the skill of article writing, we may choose to focus on opinion pieces based upon their previous creations of Surrealist-style art. This exploration could open a dialogue surrounding why specific perspectives (namely those who do not fit the dominant discourse) are silenced within societies. Similarly, when pursuing reading responses, rather than having students concentrate on efferent reading skills, we may choose to explore close, critical, and subversive reading strategies. Lessons will be largely student-centered, with a predominant component of dialogue. I will also enlist students to interview on the perceived effects of my teaching methods. This will be done on a purely volunteer basis. During each class, I will create jot notes, which I will later organize into sequential field notes. I will essentially be observing students' reactions to my new Surrealist-style pedagogies, specifically targeting the effect these strategies could

have on eliciting critical discussion. In my mind, critical discussion comprises students asking big questions and interrogating the concepts raised in our curriculum, rather than accepting them as common-sense truth. The criticality I hope to inspire will involve students drawing connections between our ELA classroom and the outside world. I will pay close attention to how my use of the strategies in promoting critical discussion (scaffolding, questioning) could affect students' verbal output, in terms of superficiality or depth. Within this laboratory of Surrealist experimentation, I aim to move away from hierarchical teacher-centered methods of information exchange. This means that students need to feel 
ownership of the ideas they craft, and be free to grapple with the difficulties these complicated concepts involve. I plan on adopting a facilitator role in sparking conversation, but ultimately hope to witness magic forming without my intervention.

\section{Conclusion}

The aims of ELA far surpass the grammar and syntax rules upon which we attach so much importance. These rules, despite being important, proceduralize ELA and pull students further away from the concepts housed within ELA. Our classrooms should instead provide spaces for students to expand their societal, cultural, and educational agency. This research project will serve as a laboratory to explore how an early twentieth century artistic/political movement can be adapted to address current societal, cultural, and educational challenges in present-day Quebec. With constraints surrounding the education domain in Quebec, from funding and ministry demands, to pressures to maintain normative standards, teachers often feel limited in their power to impart change on the world. Through a contemporary adaptation of Surrealist philosophy, this project will demonstrate and perform artistic agency in order to enable a reconceptualization and revitalization of my artless ELA.

\section{References}

Breton, A., Seaver, R., \& Lane, H. R. (1972). Manifestoes of surrealism. University of Michigan Press.

Davies, B., \& Bansel, P. (2007). Neoliberalism and education. International Journal of Qualitative Studies in Education, 20(3), 247-259.

Giroux, H. A. (1988). Teachers as intellectuals: Toward a critical pedagogy of learning. Bergin \& Garvey.

Giroux, H. A. (2016). When schools become dead zones of the imagination: A critical pedagogy manifesto. High School Journal, 99(4), 351-359.

Marantz, K., \& Rubin, W. S. (1969). Dada, surrealism, and their heritage. Art Education, 22(3), 31. Retrieved from https://doi.org/10.2307/3191289

MEES. (2019). Quebec education program: Secondary English language arts.

Rose, K., \& Kincheloe, J. L. (2003). Art, culture, \& education: Artful teaching in a fractured landscape. Peter Lang.

Rosenblatt, L. M. (2005). Literature--S.O.S.! Voices from the Middle, 12(3), 34-38.

Trend, D. (1992). Cultural pedagogy: Art, education, politics. Bergin \& Garvey. 


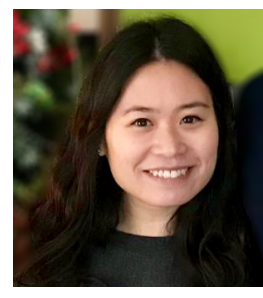

Stephanie Ho is a PhD student at McGill University and a practicing English Language Arts teacher at St. George's School of Montreal. She completed a Bachelor of Arts with a specialization in English Literature from The University of British Columbia, and a Master of Arts in Teaching and Learning with a focus on ELA education from McGill University. Her research interests include qualitative research, arts-based pedagogies, critical pedagogies, and literature studies. Stephanie is also deeply passionate about French culture and divides her time between Montreal and Paris. 
Stephanie Ho

160 | LEARNing Landscapes | Spring 2020, Vol. 13 